\title{
Use of transcatheter heart valves for a valve-in-valve implantation in patients with degenerated aortic bioprosthesis: Technical considerations and results
}

\author{
Vinayak Bapat, FRCS CTh, Rizwan Attia, MRCS, Simon Redwood, FRCP, Jane Hancock, FRCP, \\ Karen Wilson, MS, Christopher Young, FRCS CTh, and Martyn Thomas, FRCP
}

\begin{abstract}
Objective: Transcatheter aortic valve implantation has been used to treat high-risk patients with bioprosthetic valve degeneration (valve-in-valve). We report our experience with transcatheter aortic valve implantation in the treatment of degenerated biologic aortic valve prostheses and discuss factors that can influence the outcome.

Methods: From February 2009 to October 2011, 278 patients underwent transcatheter aortic valve implantation, of whom 23 underwent a valve-in-valve procedure with the Edwards Sapien valve to treat a failing bioprostheses in the aortic position. Eight of these valves were stentless bioprostheses. Thirteen patients had valve failure resulting predominantly from stenosis, and the remaining resulting from regurgitation.
\end{abstract}

Results: Mean age was $76.9 \pm 14.4$ years. The mean logistic EuroSCORE was $31.8 \% \pm 20.3 \%$ and the Society of Thoracic Surgeons score was 7.6\% $\pm 5.4 \%$. All patients were New York Heart Association class III or IV. The majority of the operations (21/23) were performed via the transapical route. Procedural success was $100 \%$, although 1 patient with a degenerated homograft needed immediate placement of a second valve because of low placement of the first. The reduction in the mean gradient was $31.2 \pm 17.06 \mathrm{~mm} \mathrm{Hg}$ to $9.13 \pm 4.9 \mathrm{~mm} \mathrm{Hg}$. In those patients with predominant aortic regurgitation (9/23), reduction in aortic regurgitation was achieved in all. The median length of stay was 11.7 days (range, 3-44 days). In-hospital and/or 30-day mortality was $0 \%$.

Conclusions: Valve-in-valve is a safe and feasible alternative to treat high-risk patients with failing aortic bioprostheses. The early results are excellent, with improvement seen in hemodynamics. (J Thorac Cardiovasc Surg 2012;144:1372-80)

Transcatheter aortic valve implantation (TAVI) has emerged as a viable treatment modality for patients with severe native aortic valve stenosis and multiple comorbidities that would typically preclude them from surgery. ${ }^{1-3}$ The "on-label" indication for TAVI using the Edwards Sapien device (Edwards Lifesciences, Irvine, Calif) is native calcific aortic stenosis in a tricuspid aortic valve in absence of any other prosthesis in the heart. ${ }^{2,3}$ Novel applications of TAVI, such as use in aortic stenosis in a bicuspid valve, ${ }^{4}$ TAVI in the presence of mitral prosthesis, ${ }^{5}$ and valve-invalve (VIV) ${ }^{6-16}$ have gathered momentum as a result of clinical need. Although small in number when compared with the number of TAVI implants, the number of VIV procedures has increased rapidly in 2011. In addition to

From the Department of Cardiothoracic Surgery and Cardiology, Guys and St. Thomas' Hospital, London, United Kingdom.

Disclosures: Authors have nothing to disclose with regard to commercial support.

Read at the 92nd Annual Meeting of The American Association for Thoracic Surgery, San Francisco, California, April 28-May 2, 2012.

Received for publication April 25, 2012; revisions received June 17, 2012; accepted for publication July 26, 2012.

Address for reprints: Vinayak Bapat, FRCS CTh, Department of Cardiothoracic Surgery, 6th Floor East Wing, St. Thomas' Hospital, Westeminster Bridge Rd, London SE21 7JB, UK (E-mail: vnbapat@yahoo.com).

$0022-5223 / \$ 36.00$

Copyright (c) 2012 by The American Association for Thoracic Surgery

http://dx.doi.org/10.1016/j.jtcvs.2012.07.104 the case reports, a few case series from single institutions and collaborative series' from multiple institutions have demonstrated feasibility and acceptable early results in selected patients. ${ }^{6-16}$ The majority of the experience in VIV has been in the treatment of failing stented bioprosthetic aortic valves and, to date, there are only isolated reports of the use of TAVI in the setting of a failing stentless bioprostheses. ${ }^{9,10,13}$

The concept and initial results have been encouraging. VIV procedures are currently undertaken if the conventional redo operation is deemed high risk. We present our VIV experience in 23 consecutive patients using the Edwards transcatheter valve (Sapien and Sapien XT). We also discuss the technical considerations and current limitations of the VIV procedure.

\section{METHODS \\ Patient Characteristics}

Between February 2009 and October 2011 we performed 23 VIV TAVI procedures for aortic bioprosthetic degeneration using the Edwards Sapien and Sapien XT valve. Mean patient age was 76.9 \pm 14.4 years (range, 29-92 years). The male-to-female ratio was 1.3:1. The mode of presentation was either severe aortic valve regurgitation $(n=9)$ or stenosis $(n=14)$. The mean logistic EuroSCORE (LES) was $31.8 \% \pm 20.3 \%$ and the mean Society of Thoracic Surgeons score was 7.6\% $\pm 5.4 \%$. Patients were discussed in a multidisciplinary team meeting (MDT) comprised of 2 cardiac surgeons, 2 intervention cardiologists, 1 noninvasive cardiologist, and 1 

Abbreviations and Acronyms
$\mathrm{BAV}=$ balloon aortic valvuloplasty
$\mathrm{CT}=$ computed tomographic
LES $=$ logistics Euroscore
MDT $=$ multidisciplinary team meeting
$\mathrm{TA}=$ transapical
TAVI $=$ transcatheter aortic valve implantation
TEE $=$ transesophageal echocardiogram
$\mathrm{TF}=$ transfemoral
VIV $=$ valve-in-valve

cardiac anesthetist. Patients were also discussed with a respiratory physician and a geriatrician when indicated. These patients were thought to be at high risk for conventional open aortic valve replacement and hence were accepted for TAVI. Patients' baseline characteristics are listed in Table 1. Of these 23 patients, 15 patients had a stented bioprosthesis and 8 patients had a stentless aortic bioprosthesis. The mean length of time from the previous aortic valve procedure for stented valves and stentless valves was $9.4 \pm 3.86$ years (range, $4-19$ years) and $14 \pm 6.21$ years, respectively. Details of various degenerated bioprostheses are listed in Table 2.

\section{Preoperative Investigations}

Three patients had undergone at least 3 open surgical procedures. Other than routine investigations, the preoperative diagnostic workup included a transthoracic echocardiogram, coronary and peripheral angiography, a noncontrast computed tomographic (CT) scan of the aorta, a respiratory function test, and a carotid Doppler examination. In addition, a preoperative transesophageal echocardiogram (TEE) was carried out in all patients with a stentless aortic bioprosthesis to determine the exact aortic annular diameter. Infective endocarditis was ruled out in all patients, which is especially important when the mode of valve failure is regurgitation. Prior operative notes were consulted when available to obtain details of the type of valve implanted, the valve size, and the surgical technique used.

\section{Operative Technique}

The procedures were all performed in a cardiac catheterization laboratory by a combined team of cardiac surgeons, cardiologists, and anesthesiologists. A perfusionist was also always present with an assembled heart-lung machine. The approach for TAVI was either transfemoral (TF) or transapical (TA). The choice of the approach was dependent on the type of bioprosthesis in situ and the size of the femoral arteries. We preferred the TA approach in all cases of stented bioprostheses and when the size of the femoral arteries was not suitable for TF access in cases of stentless bioprostheses. The techniques for both approaches have been described in detail elsewhere. ${ }^{17,18}$ For the TA approach, Ascendra 1 and Ascendra 2 delivery systems were used with Sapien and Sapien XT valves, respectively. For the TF approach, the Novoflex delivery system was used with the Sapien XT valve. All procedures were performed under fluoroscopic and TEE guidance.

In the case of stented bioprostheses, the size of the Sapien or Sapien XT valve to be implanted was determined according to the internal diameter of the degenerated prosthesis provided by the manufacturer. Valve design and fluoroscopic appearance of the degenerated bioprosthesis were studied for correct and secure placement of the Sapien valve. We have published elsewhere ${ }^{19}$ the guidance on the design, fluoroscopic appearance, and dimensions of all bioprosthetic valves as well as the ideal position of a TAVI device during the VIV procedure. A size 23-mm Sapien valve was used if the internal diameter of the valve stent was $<22 \mathrm{~mm}$, a $26-\mathrm{mm}$ prosthesis was used for an internal diameter of 23 to $25 \mathrm{~mm}$, and a $29-\mathrm{mm}$ prosthesis was used for an internal diameter of 26 to $28 \mathrm{~mm}$.

In case of a stentless bioprosthesis, the size of the new valve to be implanted was determined according to the internal diameter of the aortic annulus as in a native aortic valve measured by preoperative chest CT scan and intraoperative TEE. Internal dimensions available from the valve literature and operative records in cases of homografts were consulted. The final decision, however, was based predominantly on the intraoperative TEE.

Simultaneous fluoroscopic, angiographic, and TEE imaging were used routinely to guide the precise level for valve deployment. Balloon aortic valvuloplasty (BAV) of the degenerated valve prior to insertion of the prosthesis was not undertaken. Also, slow and gradual implantation was performed during a short phase of ventricular rapid pacing (Figure 1).

It can be difficult to visualize the level of the annulus in stentless valves because they are not as calcified as native aortic valves, the mode of presentation is most likely to be regurgitation, and, unlike stented valves, they have no radiologic markers. ${ }^{9,10}$ We have used 2 procedural modifications to achieve correct implantation in these cases, which are discussed subsequently.

\section{Postimplant Assessment}

Aortography and TEE assessment were used to determine the correct placement and function of the Sapien valve and patency of the coronary arteries. TEE assessment was used to identify and grade paravalvular leak (mild, moderate, and severe).

\section{Discharge and Follow-up}

Patients were monitored closely postoperatively per the requirements of our onsite registry, which includes patient interviews, clinical examination, and follow-up echocardiography. All patients were discharged on dual antiplatelet therapy for the first 3 months and a single agent thereafter unless contraindicated clinically.

\section{Statistical Analyses}

Continuous variables are described as mean \pm standard deviation; dichotomous or nominal variables are described as numbers and percentages. Statistical analyses were performed using SPSS (version 17.0 for Windows, SPSS Inc, Chicago, Ill).

\section{RESULTS \\ Intraoperative}

The procedural success rate was $100 \%$. One patient with a degenerated homograft had an immediate second VIV implant after low placement of the first valve resulting from difficulty in visualizing the level of the annulus. One patient had a right ventricular perforation from 1 of the transvenous pacing wires used during the procedure. This was diagnosed immediately as a pericardial effusion on the TEE and was repaired without the use of cardiopulmonary bypass. In 15 patients, a $23-\mathrm{mm}$ Sapien valve was implanted (13 stented valves and 2 stentless valves), in 6 patients a $26-\mathrm{mm}$ valve was implanted ( 2 stented valves and 4 stentless valves), and in 2 patients a $29-\mathrm{mm}$ valve was implanted (both stented valves). The sizes of in situ bioprostheses and the Sapien valve used are listed in Tables 2 and 3. The mean procedure time was $89 \pm 28.5$ minutes (range, 44-135 minutes). The mean fluoroscopy time was $11.4 \pm 4.9$ minutes (range, 5.5-18 minutes). The mean volume of 
TABLE 1. Baseline patient characteristics

\begin{tabular}{|c|c|c|}
\hline Parameter & Value $( \pm$ SD) & Range \\
\hline No. of patients & 23 & - \\
\hline Male, $\mathrm{n}$ & 13 & - \\
\hline Age, y & 79.6 & $43-92$ \\
\hline Time since valve insertion, $y$ & $14.1 \pm 6.4$ & $6-27$ \\
\hline Logistic EuroSCORE, \% & $31.6 \pm 15.3$ & $4-58.2$ \\
\hline STS score, $\%$ & $6.3 \pm 3.8$ & $3.2-18.9$ \\
\hline LVEF, \% & $48.0 \pm 12.4$ & $23-62$ \\
\hline Previous CABG or PCI & 9 & - \\
\hline Previous stroke & 2 & - \\
\hline eGFR $<60$ & 14 & - \\
\hline COPD & 6 & - \\
\hline PVD & 1 & - \\
\hline Regurgitation as mode of original valve failure, $n$ & 9 & - \\
\hline NYHA class III or IV, n & 23 & - \\
\hline
\end{tabular}

$S D$, Standard deviation, $S T S$, Society of Thoracic Surgeons; $L V E F$, left ventricular ejection fraction; $C A B G$, coronary artery bypass grafting; $P C I$, percutaneous coronary intervention; $e G F R$, estimated glomerular filtration rate; $C O P D$, chronic obstructive pulmonary disease; $P V D$, peripheral vascular disease; $N Y H A$, New York Heart Association.

contrast medium used during the procedure was $52 \mathrm{~mL}$ (range, $0-150 \mathrm{~mL}$ ). More contrast was used when treating stentless valves. After valve implantation, the mean peak gradient and mean gradient decreased from $54.54 \pm 29.2$ $\mathrm{mm} \mathrm{Hg}$ to $16.5 \pm 9.8 \mathrm{~mm} \mathrm{Hg}$ and $31.2 \pm 17.06 \mathrm{~mm} \mathrm{Hg}$ to $9.13 \pm 4.9 \mathrm{~mm} \mathrm{Hg}$, respectively. Five patients had mild paravalvular aortic regurgitation postimplantation whereas the other 18 patients had no regurgitation.

\section{Postoperative}

During the early postoperative course, there were 3 significant complications: 1 patient required reoperation for venous bleeding from the epicardium after having the procedure via the TA approach $(4.35 \%), 1$ patient developed transient right-sided weakness on postoperative day 1 that later resolved completely (4.35\%) and 4 patients developed acute kidney injury necessitating temporary hemodialysis $(17.39 \%)$. There were no postoperative myocardial infarctions, no indications for postoperative pacemaker insertion, and no wound complications. The median intensive care unit length of stay was 1 day (range, 0.5-13 days) and median length of stay was 11 days (range, 3-44 days). There was no in-hospital and/or 30-day mortality. All patients were New York Heart Association class II at the time of discharge.

\section{Follow-up Data}

There were no early or late valve reinterventions or open conversions. The mean follow-up was 8.1 months (range,

TABLE 2. Bioprosthetic valve characteristics: Baseline and after VIV

\begin{tabular}{|c|c|c|c|c|c|c|c|c|c|c|}
\hline Patient & Valve type & Valve size & ID & $\begin{array}{l}\text { Sapien valve } \\
\text { size used }\end{array}$ & $\begin{array}{l}\text { Valve } \\
\text { age, } y\end{array}$ & $\begin{array}{c}\text { Mode of } \\
\text { failure }\end{array}$ & Route & Preoperative MG & Postimplant MG & Residual AR \\
\hline & Stented & & & & & & & & & \\
\hline 1 & Perimount & 25 & 24 & 26 & 9 & S & TA & 33 & 5 & Grade 1 \\
\hline 2 & $\mathrm{CE}$ & 21 & 19 & 23 & 19 & $\mathrm{R}$ & TA & 11 & 3 & None \\
\hline 3 & $\mathrm{CE}$ & 21 & 19 & 23 & 12 & $\mathrm{R}$ & TA & 9 & 4 & None \\
\hline 4 & Soprano & 22 & 21.7 & 23 & 11 & $S$ & TA & 54 & 17 & None \\
\hline 5 & Mitraflow & 23 & 19 & 23 & 6 & $\mathrm{R}$ & TA & 5 & 12 & None \\
\hline $6^{*}$ & Mitraflow & 19 & 15.4 & 23 & 8 & $\mathrm{~S}$ & TA & 30 & 13 & None \\
\hline 7 & Perimount & 25 & 24 & 26 & 12 & $\mathrm{~S}$ & TA & 26 & 9 & None \\
\hline 8 & Perimount & 21 & 20 & 23 & 9 & $\mathrm{~S}$ & TA & 66 & 5 & None \\
\hline 9 & Perimount & 29 & 28 & 29 & 9 & S & TA & 43 & 8 & Grade 1 \\
\hline $10 *$ & $\mathrm{CE}$ & 19 & 17 & 23 & 12 & S & TA & 22 & 8 & None \\
\hline $11^{*}$ & Mosaic & 21 & 18.5 & 23 & 4 & S & TA & 46 & 4 & None \\
\hline 12 & Mitraflow & 23 & 19 & 23 & 4 & $\mathrm{R}$ & TA & 17 & 11 & None \\
\hline 13 & Perimount & 23 & 22 & 23 & 11 & S & TA & 39 & 7 & None \\
\hline $14^{*}$ & Mitraflow & 21 & 17.3 & 23 & 5 & S & TA & 31 & 20 & None \\
\hline \multirow[t]{2}{*}{15} & Perimount & 29 & 28 & 29 & 10 & $S$ & $\mathrm{TA}$ & 36 & 11 & Grade 1 \\
\hline & Stentless & & & & & & & & & \\
\hline 16 & Homograft & 23 & 23 & 26 & 15 & $\mathrm{R}$ & $\mathrm{TA}$ & 9 & 16 & None \\
\hline 17 & St. Jude Toronto SPV & 23 & 23 & 23 & 17 & $\mathrm{R}$ & TA & 33 & 10 & None \\
\hline 18 & Homograft & 22 & 22 & 26 & 13 & S & TA & 72 & 20 & None \\
\hline 19 & Homograft & 21 & 21 & 23 & 27 & $\mathrm{R}$ & $\mathrm{TF}$ & 24 & 14 & Grade 1 \\
\hline 20 & Sorin Pericarbon & 23 & 23 & 23 & 7 & $\mathrm{R}$ & TA & 31 & 8 & None \\
\hline 21 & Homograft & 23 & 23 & 26 & 14 & $\mathrm{R}$ & $\mathrm{TF}$ & 23 & 5 & None \\
\hline 22 & St. Jude Toronto SPV & 23 & & 26 & 10 & $\mathrm{R}$ & TA & 9 & 9 & Grade 1 \\
\hline 23 & Homograft & 20 & & 23 & 9 & $\mathrm{~S}$ & TA & 41 & 8 & None \\
\hline
\end{tabular}

$I D$, Internal diameter; $M G$, mean gradient; $A R$, aortic regurgitation; $C E$, Carpentier Edwards porcine valve; $S$, stenosis; $R$, regurgitation; $T A$, transapical; $T F$, transfemoral; $V I V$, value-in-value. 

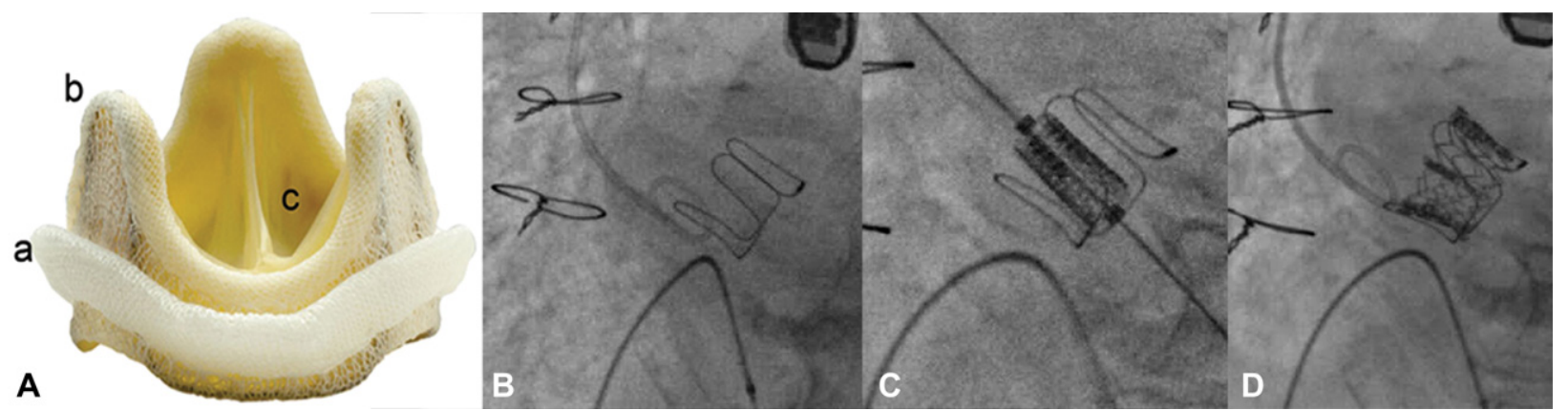

FIGURE 1. Valve-in-valve for a failed Carpentier Edwards (CE) porcine valve. A, Photograph of CE porcine valve showing relationship between sewing ring $(a)$, radio-opaque stent $(b)$, and leaflets $(c)$. B, Beginning of the procedure showing the ease with which one can obtain a good view for the procedure without use of contrast. C, Positioning of the Sapien valve within the CE porcine prosthesis. The aim is to deploy $20 \%$ below the sewing ring, which is achieved by matching the lower margin of the Sapien valve to the lower margin of the frame of CE Prosthesis. D, Fully deployed Sapien valve in an ideal position

6-24 months). There were 3 late deaths during follow-up period. One death was the result of rupture of a large abdominal aortic aneurysm on day 46 . The patient had undergone a VIV procedure successfully and was awaiting a stent procedure for the abdominal aortic aneurysm. The second death was a result of respiratory failure on day 63 , which was precipitated by pneumonia. The third death was the result of a massive gastric bleed on day 105. This patient was on single-agent antiplatelet therapy.

\section{DISCUSSION}

During the past decade, there has been an increase in valve procedures, especially aortic valve replacement. Newer generation bioprostheses are reported to last longer, and hence the age bar for implantation of a bioprosthesis has been lowered. ${ }^{20}$ It is conceivable that the majority of these patients are going to outlive the bioprosthesis and will present for redo aortic valve replacement in the future. Refinements in operative technique and postoperative management have led to low morbidity and mortality rates. ${ }^{21}$ The operative mortality for an elective redo aortic valve surgery is reported to range from $2 \%$ to $7 \%$, but this percentage can

TABLE 3. Stentless valve types and their implantation options

\begin{tabular}{ll}
\hline \multicolumn{1}{c}{ Valve name (manufacturer) } & Implantation technique \\
\hline Toronto SPV (St. Jude Medical) & Subcoronary \\
Toronto Root (St. Jude Medical) & Full root, inclusion root \\
Freestyle (Medtronic) & Full root, inclusion root, \\
& subcoronary \\
Prima Plus (Edwards LifeSciences) & Full root, inclusion root, \\
& subcoronary \\
CryoLife-O'Brien (CryoLife) & Subcoronary \\
Elan (AorTech) & Subcoronary \\
Shelhigh Superstentless (Shelhigh) & Subcoronary \\
Shelhigh Bioconduit (Shelhigh) & Full root \\
Biocor PSB/SJM (St. Jude Medical) & Subcoronary \\
Pericarbon Freedom (Sorin) & Subcoronary \\
3F Aortic Bioprosthesis (3F Therapeutics) & Subcoronary \\
\hline
\end{tabular}

increase to more than $30 \%$ in high-risk patients. ${ }^{21}$ Furthermore, redo operations are also associated with increasing morbidity and prolonged recovery. ${ }^{21}$ For this subset of patients, VIV TAVI represents a less invasive alternative to conventional redo surgery.

In 2007, Wenaweser and colleagues ${ }^{6}$ reported the first successful application of VIV TAVI using a 26-mm CoreValve (Medtronic Ltd, Minn) in the treatment of a degenerated bioprosthesis (23-mm Mitraflow) in the aortic position. Since then, multiple authors have demonstrated that VIV TAVI is technically feasible and safe, with excellent early results and low mortality using either the Sapien valve or the CoreValve. ${ }^{7-16}$ Immediate hemodynamic improvement and early results have been encouraging in this cohort of patients. The first multicenter experience using the Sapien valve was reported by Webb and associates, ${ }^{7}$ who reported 24 highrisk patients with an LES of $30.4 \% \pm 9.7 \%$ and a Society of Thoracic Surgeons score of $10.0 \% \pm 5.2 \%$. Implantation was successful in all but 1 patient, in whom the valve embolized into the distal aorta. There were no procedural deaths, and 30-day mortality was $4.2 \%$. Gotzmann and coworkers ${ }^{8}$ reported the first series using the self-expanding CoreValve. The average LES in their 5 patients was $>30 \%$. Procedural success was $100 \%$ with mild perivalvular/paravalvular leak in 2 of 5 patients and a reduction in the peak gradient from $67.6 \pm 19.3 \mathrm{~mm} \mathrm{Hg}$ to $21.2 \pm 11.4 \mathrm{~mm} \mathrm{Hg}$. Pacemaker requirements have been reported to be minimal and were none in our series. ${ }^{7,8,13-15}$ Experience in VIV for stentless bioprostheses is comparatively less. ${ }^{13}$ Traditionally, the use of TAVI has been contraindicated in patients with aortic regurgitation, which is the primary mode of failure of stentless valves. However, the inherent bulk of the stentless valve and the sutures used for its implantation can provide anchoring for the new stented valve. Nevertheless, VIV in a stentless valve is a more challenging procedure. Choice of valve used is operator dependent. Of the 17 patients reported in the literature and our 8 patients, 18 patients were treated with the Sapien valve and 7 with the CoreValve. ${ }^{13}$ 
Successful outcome of the VIV procedure is dependent on patient selection, understanding the design of the degenerated bioprosthesis, anticipation of complications, and procedural planning. It is important that the team is experienced in TAVI before undertaking a VIV procedure. We discuss here some important aspects in planning and performing a VIV case.

\section{Patient Selection}

In our center, we consider the VIV procedure only when the patient is considered high risk for a conventional redo procedure. Each patient is discussed at our MDT. ${ }^{22}$ Certain technical and design characteristics of the bioprosthetic valve in situ are studied before accepting the patient for a VIV procedure. We use the Edwards Sapien device, which currently is only available in 3 sizes: $23 \mathrm{~mm}, 26 \mathrm{~mm}$, and 29 $\mathrm{mm}$. The annulus range in which it is used to treat a native aortic stenosis is 18 to $27 \mathrm{~mm}$. Thus, using this device, a surgeon can only perform VIV in bioprosthesis valves with internal diameters ranging from 18 to $27 \mathrm{~mm}$. Similar size limitations apply for the CoreValve. ${ }^{13}$ If used in valves with a larger internal diameter, it can result in valve embolization. ${ }^{13}$ If used for a smaller diameter bioprosthesis, it would lead to underexpansion of the Sapien valve, which may interfere with its short-term and long-term hemodynamic performance and a high residual gradient. ${ }^{13,23}$ Pasic and associates, ${ }^{11}$ in one of the earliest VIV series, felt that the VIV procedure in these patients should only be undertaken as a last resort. Although many reports have since emerged demonstrating successful results in smaller valves, including 1 patient in our series with stent internal diameter $<18 \mathrm{~mm}$, we concur with them and accept these patients only when the reoperation risks are prohibitive. One also must be aware that the internal diameter of the bioprosthetic valve provided by the manufacturer is of the "stent" without leaflets. Thus, in reality, the actual internal diameter is smaller than provided. ${ }^{19}$

\section{Route for VIV}

In the initial reports of VIV, the TA route was preferred because it allowed better control and fine adjustment during valve placement. ${ }^{11}$ Furthermore, crossing of a stented bioprosthesis was much easier via the TA route and is independent of the size of the peripheral vessels. However, in centers in which both Sapien and CoreValve devices are used routinely, the choice seems to depend on the access route-CoreValve for a TF approach and Sapien for a TA approach. ${ }^{13}$ With the current modifications to the TF delivery systems for the Sapien valve (ie, Novoflex delivery system), which include a nosecone at the tip and minimal movement of the device during valve deployment, the TF route is being used increasingly for VIV procedures for a stented bioprostheses. ${ }^{14}$ The choice, however, depends entirely on the comfort of the team and its experience with a particular delivery system. We have used the TA route for stented valves, in patients with stentless valves when their peripheral arteries were not suitable for $\mathrm{TF}$, and when the aortic root anatomy was challenging (eg, a horizontal aorta).

\section{Valve Design and Characteristics}

It is of paramount importance to familiarize oneself with the design, fluoroscopic appearance, and implantation technique of the degenerated bioprosthetic valve for a successful outcome and to minimize complications such as malpositioning, valve embolization, and coronary obstruction. ${ }^{13,24}$

\section{Stented Valves}

Internal diameter. From the standpoint of VIV implantation, it is the internal diameter of the failed valve that is most relevant. We have published a complete chart of internal diameter measurements of the majority of commercially available bioprosthetic valves. ${ }^{19}$ It should be kept in mind that the disease process affecting the implanted valve can have varying effects on the internal diameter, including calcification and/or thickening of the tissue leaflets and pannus in growth. Pannus and calcification can reduce the internal diameter of the stent significantly. Hence, CT scanning and TEE are an important adjunct to available internal diameter in choosing the correct size of the TAVI valve by identifying presence of calcification and pannus, respectively. This fact is highlighted in the series published by Webb and colleagues, ${ }^{7}$ in which 2 patients had a degenerated 25-mm Carpentier-Edwards Perimount valve (internal stent diameter, $24 \mathrm{~mm}$ ). Both were treated successfully but 1 was treated with a $23-\mathrm{mm}$ Sapien valve most likely because of pannus ingrowth and the other with a 26-mm Sapien.

Fluoroscopic appearance. We have recently published a guide to fluoroscopic appearances of various surgically implanted bioprosthetic valves. ${ }^{19}$ Because the sewing ring of the bioprosthetic valve, which is sutured to the native aortic annulus, provides the most reliable rigid anchor to hold the TAVI valve in place, it is important to know the relationship between the fluoroscopic markers and the location of the sewing ring (Figure 1).

Design. In certain valves (eg, the Sorin Mitraflow and the St. Jude Trifecta), the leaflets are sutured outside the stent posts. After a VIV procedure, the leaflets are pushed farther out and this can result in coronary obstruction, especially in patients with smaller aortic root dimensions. ${ }^{24}$

\section{Stentless Valves}

During the past 2 decades, there have been a number of stentless valves that have been commercially available worldwide and each has specific recommendations regarding implantation options (Table 3).

Internal diameter. When performing TAVI in the setting of a stentless valve, we have erred on choosing a larger 
device for secure placement because the stentless valves are neither heavily calcified like native aortic valves nor have a frame like a stented bioprosthesis. Hence, a 23-mm Sapien valve was used if the internal diameter of the annulus was $<21 \mathrm{~mm}$, and a 26-mm was used for an internal diameter between $21 \mathrm{~mm}$ and $24 \mathrm{~mm}$. In the case of a borderline annulus, such as $21 \mathrm{~mm}$, a larger prosthesis (26-mm Sapien) was preferred if the leaflets were not bulky and circumferential annular calcification was minimal. We feel that this degree of oversize is essential to achieve secure anchoring of the device and is a key factor in contributing to the technical success of the procedure in those patients with primary aortic regurgitation. Self-expanding TAVI devices such as the CoreValve may have an advantage in this situation and are preferred by a few operators. ${ }^{13}$

Fluoroscopic appearance. None of the commercially available stentless valves are radio-opaque (Figure 2), which makes the procedure challenging, especially when the mode of failure is regurgitation.

Design and implantation technique. Unlike stented valves, stentless valves can be implanted using 1 of 3 techniques detailed in the Table 3. It is essential to know how the initial valve was implanted. In certain valves, such as CryoLife-O'Brien (CryoLife) and Pericarbon Freedom (Sorin), the suture lines are in proximity to the native coronary ostia, and VIV can result in coronary obstruction.

\section{VIV Positioning and Deployment: Stented Valves}

Stented bioprostheses provide good fluoroscopic landmarks for a VIV procedure. When the Sapien valve is used, the aim should be to place the valve at least $20 \%$ below the sewing ring of the bioprosthesis (Figure 1); and for the CoreValve, at least $6 \mathrm{~mm}$ below the sewing ring, $7,12,19$ which results in secure anchoring of the TAVI device. Details of VIV positioning for various types of bioprostheses have been reported elsewhere. ${ }^{7,12,19}$

\section{VIV Positioning and Deployment: Stentless Valves}

In contrast to stented bioprostheses, implantation of the Sapien valve within a stentless valve poses a different set of technical challenges. Unlike native aortic valves, the failed stentless valves usually present with aortic regurgitation and are not heavily calcified. They also lack radioopaque markers to facilitate positioning and a rigid frame to provide anchoring. In addition, the design and techniques of implantation of certain stentless valves may bring the coronary ostia in closer proximity to the annulus. To maximize precise deployment, we perform routinely a slow and gradual inflation of the prosthesis during a single short phase of rapid ventricular pacing as described by Pasic and colleagues. ${ }^{11}$

We have also used 2 procedural modifications. In the first, in the presence of free regurgitation $(n=4)$, a guidewire was placed in the left main ostium to provide a distal landmark during deployment because it was impossible to determine the correct level of the aortic annulus (Figure 2, $A$ ). In the second, when the regurgitation was less or the valve was stenotic, we placed a pigtail catheter at the base of the sinus during implantation and injected contrast during gradual inflation of the device, which provided good delineation of the aortic annulus. The pigtail was withdrawn just before complete expansion of the Sapien valve (Figure 2, $B$ ). TEE is an important adjunct in these cases and can aid in correct placement of the Sapien valve.

\section{Role of BAV}

The majority of cases of VIV are now performed without a BAV. ${ }^{13}$ Degenerated bioprosthetic leaflets can be bulky and friable, and BAV can result in embolization of the debris and leaflet tears, resulting in severe aortic regurgitation. However, one can use BAV to determine risk of coronary occlusion after VIV and to locate the level of the annulus in the case of stentless valves and stented valves without radio-opaque markers (Figure 3).

\section{Hemodynamic Results}

Uneven deployment. A TAVI valve performs best when deployed circularly throughout its length. Thus, uneven expansion can result in poor hemodynamic performance. The internal diameter of the existing bioprosthesis at the level of

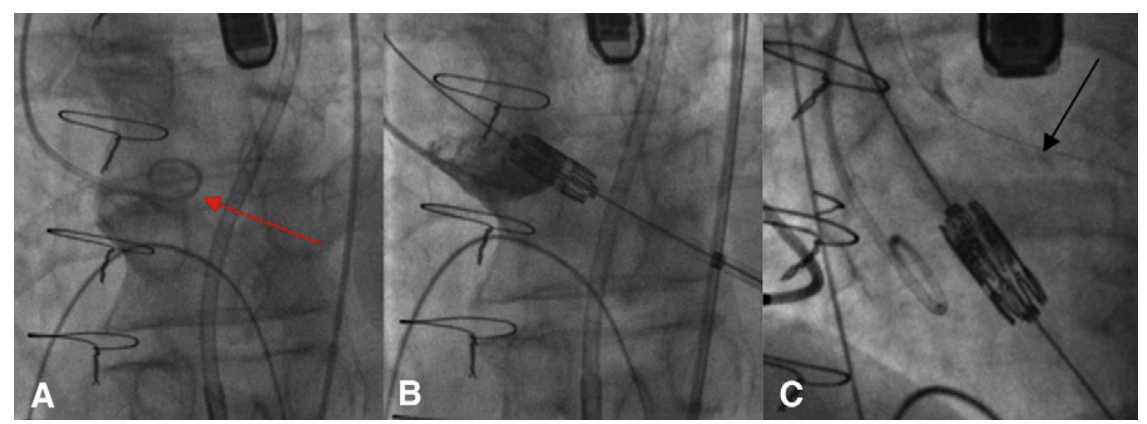

FIGURE 2. Valve-in-valve in a stentless valve. A, Fluoroscopy showing minimal calcification in a failed stentless valve (red arrow). B, Contrast injection during deployment of the Sapien device. Pigtail catheter is pulled back halfway through the deployment. C, In patients with severe regurgitation, a guidewire is placed in the left main to provide a landmark for correct deployment of Sapien valve (black arrow). 


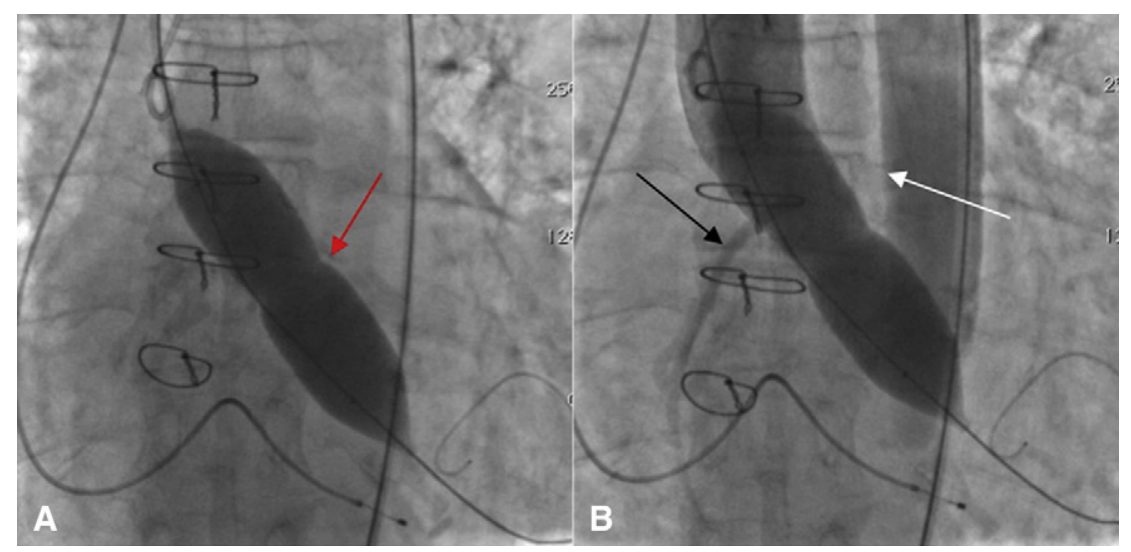

FIGURE 3. Role of balloon aortic valvuloplasty (BAV) in valve-in-valve. A, BAV showing the "waist" in the balloon delineating the level of the annulus (red arrow). B, BAV with a 20-mm balloon and simultaneous aortogram showing left main occlusion (white arrow) in a case of failed Freedom solo stentless valve. The right coronary artery was unobstructed (black arrow).

inflow is the most limiting diameter for TAVI valve expansion because the stent posts can be splayed outward. Uneven deployment can result in a conical or dumbbellshaped deployment when using the Sapien valve (Figure 4). This problem will only be minimized when a wider range of sizes of TAVI valves becomes available to ensure an exact match.

Residual gradient. As a result of the placement of a valve inside another valve, there is a concern about significant residual gradients resulting from a "Russian nested doll" effect. Postprocedural gradients are in the range of 10 to 22 $\mathrm{mm} \mathrm{Hg}$ in most series. ${ }^{711,13,14}$ Higher residual gradients are observed in smaller bioprostheses. ${ }^{13}$ Eggerbrecht and associates $^{25}$ reported a trend of favorable hemodynamics when using the CoreValve in small bioprostheses (21 $\mathrm{mm}$ ) compared with the Sapien valve, but the numbers were too small to draw definite conclusions. The main concern is in patients with a bioprosthesis with an internal diameter $<19 \mathrm{~mm}$. In our series, 4 patients with an internal diameter of $\leq 19$ underwent VIV with a 23-mm Sapien valve. Two patients had higher residual mean gradients but continue to have excellent symptomatic improvement.

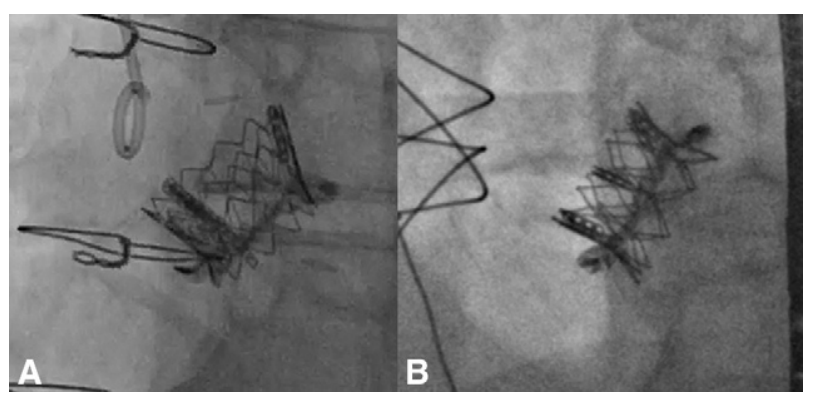

FIGURE 4. Uneven expanssion of the Sapien valve after a VIV procedure. A, Final shape is conical or "top hat" when deployed $<20 \%$ below the sewing ring. B, Final shape is dumbell-shaped when deployed $>20 \%$ below the sewing ring.
Similar observations have been reported by other authors, and hence VIV may be offered in such cases when there is no surgical option. ${ }^{7,11,12,14}$

Residual regurgitation. Residual regurgitation can be the result of a paravalvular/perivalvular leak or a transvalvular leak. A transvalvular leak can be a result of underexpansion or an uneven expansion of the TAVI device. ${ }^{13}$ In our series, 6 patients had residual grade 1 leaks, all of which were paravalvular. Residual regurgitation resulting from a paravalvular leak is a significant problem when TAVI is used to treat the native valve, but most published series reporting experience with VIV have observed minimal residual regurgitation, similar to our experience. ${ }^{7,11,13,14}$ A degenerated bioprosthesis provides a circular annulus and less bulky leaflets, which allow an even expansion and better opposition of a TAVI device, thus resulting in a less degree of paravalvular leak when compared with a native stenotic aortic valve.

\section{Future Direction}

VIV implantation has been performed successfully in degenerated bioprostheses in the mitral, tricuspid, and pulmonary positions. ${ }^{7,15,16}$ Work is in progress from various groups to provide clinicians with robust bench data on this indication, and there is a possibility of trials for Conformite Europeene (CE) mark in the near future. Availability of more sizes of TAVI devices and specific TAVI devices for VIV will facilitate the procedure and ensure good longterm results.

\section{Study Limitations}

This is a large case series with short follow-up. Although we have shown feasibility and good short-term results by using a single device, larger studies and/or trials and longterm data are needed to understand efficacy of this treatment modality. 


\section{CONCLUSIONS}

VIV is a useful alternative in selected patients who are at high risk for undergoing an open surgical procedure. Case selection is of paramount importance and should be discussed during an MDT. Patients with small bioprosthetic valves may be treated with VIV if the risk of conventional surgery is prohibitive. It is important to be familiar with the details of the in situ bioprostheses, including type, size, fluoroscopic appearance, and method of implantation, to have a successful outcome. Early results reveal improvement in hemodynamics and amelioration of symptoms, but longer follow-up with more patients is needed.

\section{References}

1. Cribier A, Eltchaninoff H, Bash A, Borenstein N, Tron C, Bauer F, et al. Percutaneous transcatheter implantation of an aortic valve prosthesis for calcific aortic stenosis: first human case description. Circulation. 2002;106:3006-8.

2. Leon MB, Smith CR, Mack M, Miller DC, Moses MW, Svensson LG, et al. Transcatheter aortic-valve implantation for aortic stenosis in patients who cannot undergo surgery. N Engl J Med. 2010;363:1597-607.

3. Thomas M, Schymik G, Walther T, Himbert D, Lefevre T, Treede H, et al. Oneyear outcomes of cohort 1 in the Edwards SAPIEN Aortic Bioprosthesis European Outcome (SOURCE) registry: the European Registry of Transcatheter Aortic Valve Implantation Using Edwards SAPIEN Valve. Circulation. 2011; 124:425-33.

4. Wijesinghe N, Ye J, Rodes-Cabau J, Cheung A, Velianou JL, Natarajan MK, et al. Transcatheter aortic valve implantation in patients with bicuspid aortic valve stenosis. JACC Cardiovasc Interv. 2010;3:1122-5

5. Attia R, Bapat V. Transcatheter aortic valve implantation for treatment of failing homograft with pre-existing mechanical mitral prosthesis. Catheter Cardiovasc Interv. 2011;25. Epub ahead of print.

6. Wenaweser P, Buellesfeld L, Gerckens U, Grube E. Percutaneous aortic valve replacement for severe aortic regurgitation in degenerated bioprosthesis: the first valve in valve procedure using the CoreValve revalving system. Catheter Cardiovasc Interv. 2007;70:760-4

7. Webb JG, Wood DA, Ye J, Gurvitch R, Masson JB, Rodes-Cabau J, et al. Transcatheter valve-in-valve implantation for failed bioprosthetic heart valves. $\mathrm{Circu}$ lation. 2010;121:1848-57.

8. Gotzmann M, Mugge A, Bojara W. Transcatheter aortic valve implantation for treatment of patients with degenerated aortic bioprostheses: valve-in-valve technique. Catheter Cardiovasc Interv. 2010;26:1000-6.

9. Attias D, Himbert D, Hvass U, Vahanian A. "Valve-in-valve" implantation in a patient with stentless bioprosthesis and severe intraprosthetic aortic regurgitation. J Thorac Cardiovasc Surg. 2009;138:1020-2.

10. Schmoeckel M, Boekstegers P, Nikolaou K, Reichart B. First successful transapical aortic valve implantation after aortic allograft replacement. J Thorac Cardiovasc Surg. 2009;138:1016-7.

11. Pasic M, Unbehaun A, Dreysse S, et al. Transapical aortic valve implantation after previous aortic valve replacement: clinical proof of the "valve-in-valve" concept. J Thorac Cardiovasc Surg. 2011;142:270-7.

12. Piazza N, Bleiziffer S, Brockmann G, Hendrik R, Deutsch M, Opitz A, et al. Transcatheter aortic valve implantation for failing surgical aortic bioprosthetic valve: from concept to clinical application and evaluation (part 1). JACC Cardiovasc Interv. 2011;4:721-32.

13. Piazza N, Bleiziffer S, Brockmann G, Hendrik R, Deutsch MA, Opitz A, et al. Transcatheter aortic valve implantation for failing surgical aortic bioprosthetic valve: from concept to clinical application and evaluation (part 2). JACC Cardiovasc Interv. 2011;4:733-42.

14. Latib A, Lelasi A, Montorfano M, Maisano F, Chieffo A, Cioni M, et al. Transcatheter valve-in-valve implantation with the Edwards SAPIEN in patients with bioprosthetic heart valve failure: the Milan experience. Eurointervention. 2012; 7:1275-84.

15. Cheung A, Soon JL, Webb JG, Ye J. Transatrial transcatheter tricuspid valvein-valve technique. J Cardiac Surg. 2012;27:196-8.

16. Cheung A, Gurvitch R, Ye J, Wood D, Lichtenstein SV, Thompson C, et al. Transcatheter transapical mitral valve-in-valve implantation for a failed bioprosthesis: a case series. J Thorac Cardiovasc Surg. 2011;141:711-5.
17. Walther T, Mollmann H, Linden A, Kempfert J. Transcatheter aortic valve implantation transapical: step by step. Semin Thorac Surg. 2011;23:55-61.

18. Wilson A, Toggweiler S, Webb JG. Transfemoral aortic valve replacement with the SAPIEN XT valve: step by step. Semin Thorac Cardiovasc Surg. 2011;23:51-4.

19. Bapat V, Mydin I, Chadalavada S, Tehrani H, Attia R, Thomas M. A guide to fluoroscopic identification and design of bioprosthetic valves: a reference for valvein-valve procedure. Catheter Cardiovasc Interv. 2012. Epub ahead of print.

20. Brown JM, O’Brien SM, Wu C, Sikoka JA, Griffith BP, Gammie JS. Isolated aortic valve replacement in North America comprising 108,687 patients in 10 years: changes in risks, valve types, and outcomes in the Society of Thoracic Surgeons national database. J Thorac Cardiovasc Surg. 2009;137:82-90.

21. Chan V, Malas T, Lapierre H, Bhoodwani M, Lam BK, Rubens FD, et al. Reoperation of left heart valve bioprosthesis according to age at implantation. Circulation. 2011;124:S75-80.

22. Dworakowski R, MacCarthy PA, Monaghan M, Redwood S, El-Gamel A, Young $\mathrm{C}$, et al. Transcatheter aortic valve implantation for severe aortic stenosis: a new paradigm for multidisciplinary intervention: a prospective cohort study. Am Heart J. 2010;160:237-43.

23. Azadani AN, Jaussaud N, Matthews PB, Chuter TA, Ge L, Guy TS, et al. Aortic valve-in-valve implantation: impact of transcatheter-bioprosthesis size mismatch. J Heart Valve Dis. 2009;18:367-73.

24. Gurvitch R, Cheung A, Bedogni F, Webb JG. Coronary obstruction following transcatheter aortic valve-in-valve implantation for failed surgical bioprostheses. Catheter Cardiovasc Interv. 2011;77:439-44.

25. Eggerbrecht $H$, Schafer U, Treede H, Boekstegers $P$, Babin-Ebell J, Ferrari M, et al. Valve-in-valve transcatheter aortic valve implantation for degenerated bioprosthetic heart valves. JACC Cardiovasc Interv. 2011;4: 218-27.

\section{Discussion}

Dr Mathew R. Williams (New York, NY). I would like to thank the American Association for Thoracic Surgery for the honor of discussing this paper and thank you, Dr Bapat, for sending the paper to me ahead of time. I had the pleasure of discussing a somewhat similar paper last year at this meeting, looking at VIV, and it is nice as a U.S. physician to now be discussing it with actually having experience with this procedure now that we have an approved system.

I will say that doing a transcatheter VIV is actually one of my favorite procedures and I think it is really remarkable how well these patients do. With this procedure in particular, it gives us the advantages of the transcatheter procedure, a less invasive procedure with better recovery, but I think we also avoid some of the bad things that have been affiliated with transcatheter valvesnamely, the paravalvular leak rate should probably be almost nothing in most cases, and in theory we might have a lower stroke rate, but we certainly don't know that.

I am very impressed with your experience. It is still based on 23 patients, so I certainly don't have anything to be critical of your presentation, but would rather ask you some questions related to how you conduct your clinical practice.

The first question is, I am wondering whether, given that this is such a great procedure for a degenerated bioprosthesis, have you changed your clinical practice in patients who are having surgical aortic valve replacements? Namely, are you putting tissue valves in younger patients? And if so, given what you discussed with the gradients, are you perhaps more aggressive about a root enlargement in somebody who you wouldn't normally if you might be operating on an 80-year-old who you don't expect to be operating on again?

The second question is about the approach. I am wondering why you did so many of these TA. I do understand that in some of the 
first reports of this procedure it was recommended that it be done TA for better control, but I will be honest, I haven't really understood that, and our approach has been just to do the procedures. If they have good access, we will do a TF; if they don't, we will certainly do a TA.

And then the final question, which you alluded to a little bit, in the largest experience that was presented at the Transcatheter Valve Therapy meeting this year, there was a surprisingly high incidence, or a higher incidence than I expected-it's still a low incidence-of coronary occlusion, which was most prominent with stentless valves and, in particular, actually, the Mitroflow valve, and I think 3 of your patients had the Mitroflow valve. I am wondering if you could comment on how you are addressing that potential fatal complication.

Dr Bapat. Thank you, Dr Williams, for your questions. My practice hasn't changed, but patients are well informed now that we are doing a VIV procedure, and patients come to us saying they want a bioprosthetic valve because there is a good chance that in 10 to 15 years they will have a keyhole treatment by which we will take care of it. I give the choice to the patients regarding what kind of valve they are going to have, depending on their lifestyle and aversion to warfarin.

Yes, if I do a bioprosthetic valve in younger patients, my aim is to put a larger bioprosthesis. Having performed TAVI as well as an open aortic valve practice, that is going to be very important, because these patients are going to present at an age of maybe 75 or 80 , and if I can at least put a 26 size Sapien valve, or whichever device is available at that time, it will definitely add 10 more years in each patient.

Your second question: Why TA? Absolutely. It was initially thought that it gives you better tactile feel, better control while you are inflating it slowly. Also if you remember with the RetroFlex 1 system, which lacked a nosecone crossing the valve, there were some catastrophic events such as leaflet tears, or sometimes the valve got stuck on the stent. And I think that is the only reason why units like ours have gone ahead and have just done TA. But we are changing with the availability of the NovaFlex system. And I completely agree with you that it should be taken the same way we treat the native aortic valve; the access should be determined by that.

And your last question about coronary obstruction, we are very cautious, and, as I mentioned in my presentation, with designs like Mitroflow, designs like Trifecta, but I think all the designs, especially in small valves, these patients tend to have small sinuses of Valsalva, and then we can do a BAV to check if there is a coronary obstruction. If I am correct, there are only 3 cases reported in the literature currently -2 with Mitroflow and 1 with Mosaic - that have led to coronary obstruction. However, I think in real life probably the incidence is much higher than that.

Dr Jahanzaib Idrees (Cleveland, Ohio). I have 1 question regarding younger patients in whom it would be more reasonable to place a mechanical valve. There are patients who are hesitant to get a mechanical valve and they don't want to take Coumadin. So I am interested in knowing your perspective. Would you be confident in placing a bioprosthetic valve in that patient based on what you explained your results with so that maybe later on, if the valve wears off, you can do a VIV procedure? What would be your approach to convince that patient? Will you tell him to get a mechanical valve or would you tell him that a bioprosthetic valve may still be an option given the feasibility of a VIV procedure? What would be your approach in that regard?

Dr Bapat. As I said before, the approach hasn't changed, because this should still be the result for high-risk patients. We don't know how long these valves are going to last. As I showed you before, circularity is very important, and in TAVI procedures currently, you can't control circularity in these patients. So I think options to the patients still remain the same. If they are young, they should decide whether they need to have a mechanical or bioprosthetic valve. I don't make the choice for them.

Dr Ludwig Karl von Segesser (Lausanne, Switzerland). Congratulations for a nice series. You have not been very specific about the gradients in the smaller sizes of your valves. Could you specify about the $21 \mathrm{~mm}$ and the $19 \mathrm{~mm}$ especially?

Dr Bapat. Certainly. I think the residual gradients in all those patients were much, much higher. So we had a drop-off average gradient from $30 \mathrm{~mm} \mathrm{Hg}$ to $9 \mathrm{~mm} \mathrm{Hg}$, but in these patients we had residual gradients, so mean gradients of at least $20 \mathrm{~mm} \mathrm{Hg}$. However, we undertook them as the last option, and the patients had very good symptomatic relief.

Dr Adrian Jeremy Levine (Stoke-on-Trent, UK). Very impressive work. Do you do balloon valvuloplasty for all valves of your late series? We started, like you, the first 1 or 2, not doing it, but now we have gone back and we balloon valvuloplasty all of ours. What about you?

Dr Bapat. We have gone the other way around. In fact, in our first case we did a BAV. I think the difference is because we do the TA. You don't need to do a BAV. And the procedure is very short, only one pacing episode, and, again, I think doing a BAV - unless you are worried about coronary obstruction-I think there is no need to do a BAV. 